\title{
Photoacoustic optical properties at UV, VIS, and near IR wavelengths for laboratory generated and winter time ambient urban aerosols
}

\author{
M. Gyawali ${ }^{1}$, W. P. Arnott ${ }^{1}$, R. A. Zaveri ${ }^{2}$, C. Song $^{2}$, H. Moosmüller ${ }^{3}$, L. Liu ${ }^{4}$, M. I. Mishchenko ${ }^{4}$, L.-W. A. Chen ${ }^{3}$, \\ M. C. Green ${ }^{3}$, J. G. Watson ${ }^{3}$, and J. C. Chow ${ }^{3}$ \\ ${ }^{1}$ Physics Department, University of Nevada, Reno, Nevada System of Higher Education, 1664 N. Virginia Street, Reno, \\ NV, 89557, USA \\ ${ }^{2}$ Atmospheric Sciences and Global Change Division, Pacific Northwest National Laboratory, Richland, WA, 99352, USA \\ ${ }^{3}$ Desert Research Institute, Nevada System of Higher Education, 2215 Raggio Parkway, Reno, NV, 89512, USA \\ ${ }^{4}$ NASA Goddard Institute for Space Studies, 2880 Broadway, New York, NY 10025, USA \\ Correspondence to: M. Gyawali (madhug@unr.edu)
}

Received: 26 August 2011 - Published in Atmos. Chem. Phys. Discuss.: 8 September 2011

Revised: 21 February 2012 - Accepted: 24 February 2012 - Published: 8 March 2012

\begin{abstract}
We present the laboratory and ambient photoacoustic (PA) measurement of aerosol light absorption coefficients at ultraviolet wavelength (i.e., $355 \mathrm{~nm}$ ) and compare with measurements at 405, 532, 870, and $1047 \mathrm{~nm}$. Simultaneous measurements of aerosol light scattering coefficients were achieved by the integrating reciprocal nephelometer within the PA's acoustic resonator. Absorption and scattering measurements were carried out for various laboratorygenerated aerosols, including salt, incense, and kerosene soot to evaluate the instrument calibration and gain insight on the spectral dependence of aerosol light absorption and scattering. Ambient measurements were obtained in Reno, Nevada, between 18 December 2009 and 18 January 2010. The measurement period included days with and without strong ground level temperature inversions, corresponding to highly polluted (freshly emitted aerosols) and relatively clean (aged aerosols) conditions. Particulate matter (PM) concentrations were measured and analyzed with other tracers of traffic emissions. The temperature inversion episodes caused very high concentration of $\mathrm{PM}_{2.5}$ and $\mathrm{PM}_{10}$ (particulate matter with aerodynamic diameters less than $2.5 \mu \mathrm{m}$ and $10 \mu \mathrm{m}$, respectively) and gaseous pollutants: carbon monoxide (CO), nitric oxide (NO), and nitrogen dioxide $\left(\mathrm{NO}_{2}\right)$. The diurnal change of absorption and scattering coefficients during the polluted (inversion) days increased approximately by a factor of two for all wavelengths compared to the clean days.
\end{abstract}

The spectral variation in aerosol absorption coefficients indicated a significant amount of absorbing aerosol from traffic emissions and residential wood burning. The analysis of single scattering albedo (SSA), Ångström exponent of absorption (AEA), and Ångström exponent of scattering (AES) for clean and polluted days provides evidences that the aerosol aging and coating process is suppressed by strong temperature inversion under cloudy conditions. In general, measured UV absorption coefficients were found to be much larger for biomass burning aerosol than for typical ambient aerosols.

\section{Introduction}

Atmospheric aerosols impact air quality and Earth's radiation balance. Aerosol light scattering redistributes electromagnetic energy in the atmosphere, whereas light absorption transforms it into thermal energy by heating absorbing aerosols and their surroundings. The absorption and scattering coefficients of aerosol are needed for modeling atmospheric radiation transfer (Clarke et al., 1987). These quantities are challenging to quantify and are associated with large uncertainties in the radiative forcing (Bergstrom et al., 2007, 2009). Aerosol optical properties depend on particle size, morphology, refractive index (RI), and wavelength of 
electromagnetic radiation and must be specified over the entire solar spectrum (Levoni et al., 1997).

Carbonaceous aerosols account for much of the atmospheric particulate matter mass that affects incoming solar radiation via scattering and absorption (Sun et al., 2007). These aerosols consist of two major carbon components, elemental carbon (EC), and organic aerosol (OA) (Seinfeld and Pandis, 2006). Black carbon (BC) is operationally defined through an aerosol light absorption measurement; for near infrared wavelengths BC strongly correlates with EC due to its quasi-graphitic structure. $\mathrm{BC}$ is emitted as a result of incomplete combustion of carbon-rich fuels. The other component, OA, though present in much higher mass concentrations than $\mathrm{BC}$ for ambient samples, is more elusive as its origins as well as optical and chemical properties vary greatly with source, transformation, and sink (D'Alessio et al., 1998). OA exhibits many molecular forms that have different physical and chemical properties and often exists independently of BC (Jacobson et al., 2000). The OA that is directly emitted from combustion or biogenic processes is referred to as primary organic aerosol (POA). OA is also formed in-situ through the oxidation of gaseous organic precursors that transfer to the aerosol phase by condensation or nucleation, referred to as secondary organic aerosol (SOA). SOA formation involves two processes: gas-phase chemical transformation and change of phase. Photochemical transformation also promotes inorganic aerosol formation.

$\mathrm{BC}$ strongly absorbs throughout the entire solar spectrum (Horvath, 1993; Moosmuller et al., 2009). The refractive index (RI) of BC depends predominantly on fuel type, combustion phase, degree of graphitization, and atmospheric processing (Andreae and Gelencsér, 2006; Bond and Bergstrom, 2006). Pure carbon (i.e., graphitic state) has RI as large as $2+1 \mathrm{i}$, where the real and imaginary parts of RI impact both light scattering and absorption. The formation of $\mathrm{BC}$ through pyrolysis of hydrocarbon fuels is a complicated process. This process leads to the formation of complex substances like oils, tars, and solids, while the adsorption and continuing elimination of hydrogen at higher temperature results in an increase in crystal size and graphitization of the fuel (Grisdale, 1953). For instance, diesel soot appears as an onion-shell structure of nano crystalline graphite having domain sizes of 2-3 nm (Wentzel et al., 2003). Out of the four valence electrons of carbon atoms in graphite, three are in the hybrid $\mathrm{sp}^{2}$ state and one is in the $\mathrm{p}$ state. The electrons in the hybrid state form $\sigma$ bonds and those in the $p$ state form $\pi$ bonds due to the mutual overlapping above and below the graphitic plane, and become delocalized (Bond and Bergstrom, 2006). Electrons in the $\pi$ bond can move rather freely and absorb electromagnetic radiation from at least the $\mathrm{UV}$ to the near IR. Electrons in $\sigma$ bonds are effective in ultraviolet (UV) absorption.

While BC aerosols absorb strongly over the entire solar spectrum, some OA absorbs efficiently in the UV and blue regions (Barnard et al., 2008; Bergstrom et al., 2007; Bond,
2001; Chakrabarty et al., 2010; Jacobson, 1999; Kirchstetter et al., 2004; Martins et al., 2009; Roden et al., 2006). These organic materials appear yellowish/brownish and are known as "brown carbon" (Andreae and Gelencsér, 2006). Brown carbon $(\mathrm{BrC})$ is commonly found in secondary and biomass burning aerosols (e.g. Andreae and Gelencsér, 2006; Chakrabarty et al., 2010; Chen et al., 2010). UV radiation encompasses only $10 \%$ of the total solar irradiance, so details of its direct radiative forcing are often ignored in climate modeling (Corr et al., 2009). There have been many investigations of aerosol optical properties in the visible spectrum, though in situ measurements of UV absorption by ambient aerosols are rare (Kikas et al., 2001; Taylor et al., 2008).

Radiative transfer in the UV with respect to photochemistry has motivated us to develop a new photoacoustic instrument and nephelometer that can measure in situ aerosol absorption and scattering coefficients at UV wavelengths. Ajtai et al. (2010) and Ajtai et al. (2011) have previously demonstrated the use of a four-wavelength (including 266 and $355 \mathrm{~nm}$ ) photoacoustic instrument measuring aerosol light absorption coefficients for laboratory-generated and ambient aerosols. UV radiation is the dominant driver of atmospheric chemistry. The photo dissociation of gaseous species due to UV radiation is responsible for smog and ozone formation in the troposphere (Jacobson, 1999). Most photolysis is due to UV radiation between 290 to $420 \mathrm{~nm}$ (Hofzumahaus and Kraus, 2002). Jacobson (1999) found that the nearly $50 \%$ decline in UV radiation within the boundary layer (BL) in Los Angles was due to substantial UV absorption by nitrated and aromatic aerosols and gaseous species. A very recent study indicated nighttime formation of particulate organic nitrate and organosulfate species in coal-fired power plant plumes (Zaveri et al., 2010) that may also absorb UV radiation the following day.

This study reports multispectral photoacoustic absorption and scattering measurements at wavelengths $355,405,532$, 870 , and $1047 \mathrm{~nm}$ for laboratory-generated aerosol as well as for ambient aerosol during the months of December 2009 and January 2010. The hourly concentrations of $\mathrm{PM}_{2.5}$ and $\mathrm{PM}_{10}$ and gaseous pollutants $\left(\mathrm{CO}, \mathrm{NO}\right.$, and $\left.\mathrm{NO}_{2}\right)$ are also analyzed for the same period. The simultaneous measurement of aerosol optical properties at multiple wavelengths provides an improved coverage of the solar spectrum and offers a way to single out the spectral signature of $\mathrm{BC}$ and $\mathrm{OA}$ aerosols. Nevertheless, our previous investigation (Gyawali et al., 2009) suggests that even non-absorbing coatings on $\mathrm{BC}$ can be disguised as $\mathrm{BrC}$ or light absorbing $\mathrm{OA}$, so it is not always possible to separate the effects of coatings on amplifying aerosol absorption and intrinsic absorption by the coating (Jacobson et al., 2000). 


\section{Photoacoustic instrument and laboratory generated aerosols}

\subsection{Instrument description}

The photoacoustic instrument (PA) is one of the few devices that provide the fundamental in-situ measurement of light absorption coefficients for suspended particles. The detailed working mechanism, measurement accuracy, evaluation and calibration of PA have been described previously (Arnott et al., 2000, 2005a,b; Lewis et al., 2008; Moosmüller et al., 1998). Here we describe the basic principle and calibration technique applied for the $355 \mathrm{~nm}$ instrument. The $355 \mathrm{~nm}$ instrument uses a compact crystal laser system, a diode pumped Nd:YAG laser with frequency tripling to produce $355 \mathrm{~nm}$ laser output. The laser is actively Q-switched with a pulse repetition rate adjustable from 1 to $20 \mathrm{kHz}$. In the operation of the PA, sample air is continuously introduced into the acoustic resonator section and is illuminated by laser radiation, power-modulated at the acoustic resonance frequency. The radiation is absorbed by particles within the sample air, and is assumed to be immediately transferred to the surrounding air as heat. The associated pressure change contributes to a standing wave in the resonator that is detected by a microphone located at a pressure anti-node (Arnott et al., 1999). The simultaneous light scattering measurement is carried out with a cosine-weighted sensor positioned at the centre of the cavity to act as a reciprocal nephelometer (Lewis et al., 2008; Abu-Rahmah et al., 2006). The sensor is fiber coupled to a photomultiplier tube (PMT) for light scattering detection. A piezoelectric transducer positioned at a pressure anti-node of the resonator cavity is used periodically to determine the resonance frequency and quality factor of the resonator. The absorption and scattering coefficients measurements have $5 \%$ and $15 \%$ uncertainty for sub-2.5-micron diameter particles (Lewis et al., 2008). The detection limit of $355 \mathrm{~nm}$ instrument for absorption coefficient was on the order of $0.4 \mathrm{Mm}^{-1}$.

Light absorption and scattering measurements in this study were made simultaneously with a dual-wavelength PA operating at 405 and $870 \mathrm{~nm}$ (Lewis et al., 2008), and two singlewavelength PAs operating at 532 and $1047 \mathrm{~nm}$ (Arnott et al., 2000, 2005b). Prior to the ambient measurements, all PAs were calibrated and their performance was evaluated by generating a wide range of absorbing and scattering aerosol in the laboratory as described by Lewis et al. (2008).

The light absorption coefficient, $\beta_{\mathrm{abs}}$, in dimension of inverse length is obtained from,

$\beta_{\mathrm{abs}}=\frac{P_{\mathrm{m}} A_{\mathrm{res}}}{P_{\mathrm{L}}(\gamma-1)} \frac{\pi^{2} f_{0} \cos \left(\phi_{\mathrm{m}}-\phi_{\mathrm{L}}\right)}{Q}$,

where $P_{\mathrm{m}}$ and $P_{\mathrm{L}}$ are the measured microphone pressure and laser power at the resonance frequency $f_{o}, A_{\text {res }}$ is the resonator cross-sectional area, $Q$ is the quality factor, $\gamma$ is the ratio of isobaric and isochoric specific heats of air, and $\phi_{\mathrm{m}}$ and $\phi_{\mathrm{L}}$ are the electric phases of the microphone pressure and laser power measurements, respectively. The resonance frequency and quality factor depend on temperature, pressure, and relative humidity. For the sample air, these quantities are measured by pressure, temperature, and relative humidity sensors located in the sample line downstream of the resonator.

The scattering coefficient, $\beta_{\mathrm{sca}}$ in dimension of inverse of length, is obtained from

$\beta_{\mathrm{sca}}=\alpha \frac{\left|P_{\mathrm{PMT}}\right|}{\left|P_{\mathrm{L}}\right|}$

where $\alpha$ is the calibration factor determined at the time of instrument calibration and $\left|P_{\mathrm{PMT}}\right|$ and $\left|P_{\mathrm{L}}\right|$ are the magnitudes of Fourier transform of the PMT and laser power at the resonance frequency, respectively.

\section{Calibration}

Calibration of the photoacoustic instruments, for light absorption, is accomplished in three ways. First and foremost, the instrument can be independently prepared for quantitative measurements from a fundamental perspective. We have derived and verified a 1-D model equation for the acoustical resonator taking into account the operating frequency, microphone calibration, laser power calibration, resonator quality factor measurement, resonator cross sectional area, and gas constant for air (ratio of specific heats) (Arnott, et al., 1999). This method has been evaluated by us and others using light absorption by $\mathrm{NO}_{2}$ at $532 \mathrm{~nm}$ (Arnott, et al., 2000). We use a commercially available microphone-calibrator for the microphone calibration of the $1^{\prime \prime}$ microphone that we use in the instrument. Propagating error through this fundamental procedure for instrument calibration, we arrive at a calibration accuracy of $\pm 5 \%$, with the weakest part of the calibration procedure associated with the laser power measurement. Then, as long as we can measure laser power accurately at other wavelengths, we can use the same microphone calibration for any wavelength since the microphone is a "color blind" sensor. $\mathrm{NO}_{2}$ photolysis at $405 \mathrm{~nm}$ and shorter wavelengths prevents direct measurement of path extinction $=$ photoacoustic absorption since some of the absorbed optical power goes into bond breaking rather than to heat. $\mathrm{O}_{2}$ has been investigated as a calibration gas in the oxygen $\mathrm{A}$ band spectral region near $760 \mathrm{~nm}$ (oxygen A band, tunable laser) but in this wavelength range, gaseous light absorption involves significant relaxation processes that are mediated by water vapor (Gilles et al., 2010; Tian et al., 2009). In this case, the molecular physics of oxygen is very interesting, but the accuracy of using gas calibration for aerosol light absorption measurement is less assured. The use of Absorption = Extinction - Scattering for aerosol is an evaluation of the calibration achieved by the fundamental method. Extinction and scattering measurements both have uncertainties in excess of that achievable by the fundamental calibration method. For 

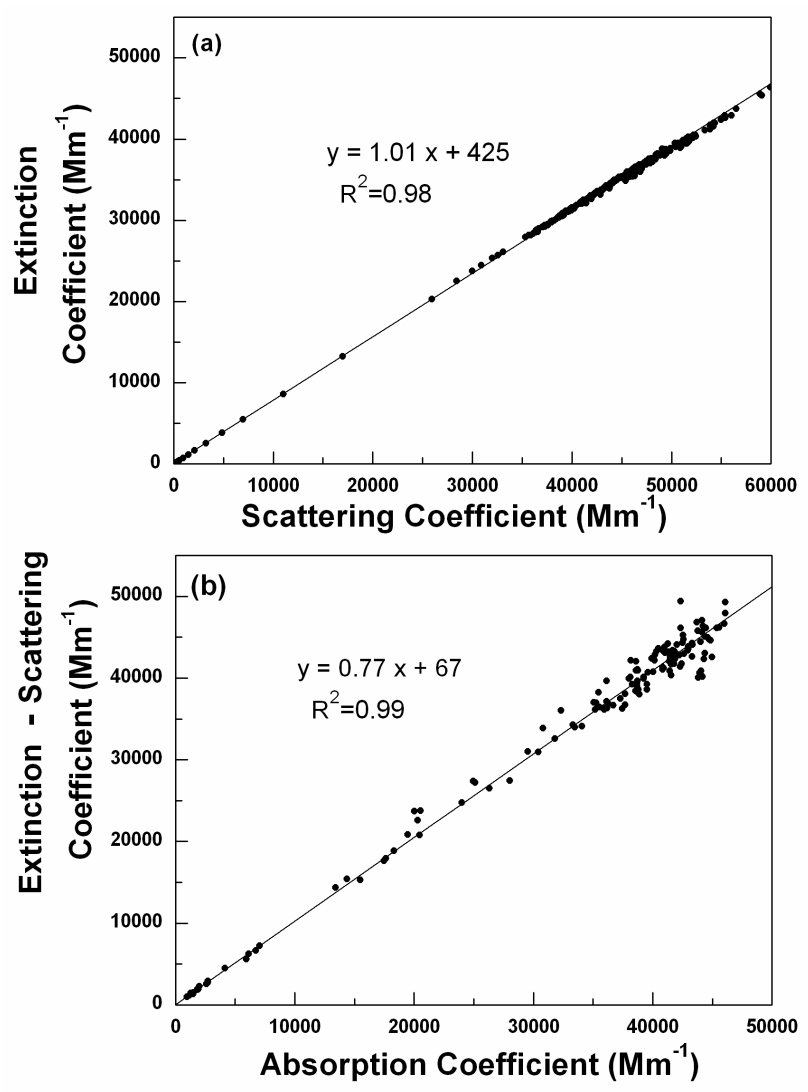

Fig. 1. Plots of $355 \mathrm{~nm}$ calibration curves for (a) scattering measurements of negligibly absorbing salt aerosol, and (b) absorption measurements of kerosene soot.

the calibration of PA operating at $355 \mathrm{~nm}$, high concentrations of laboratory-produced purely scattering (table salt) and strongly absorbing (kerosene soot) aerosols were used, which resulted in a measurable attenuation of the laser beam intensity in the resonator. The salt was dissolved in water and nebulizers were used to produce airborne droplets from the salt solution. Dried salt aerosols were introduced into the resonator for scattering calibration. A fast photodiode attached to an integrating sphere is used to determine the laser power. The extinction of light passing through aerosol can be expressed using Bouger-Lambert's law,

$$
I=I_{0} \exp \left(-\beta_{\text {ext }} \cdot L_{\text {res }}\right)
$$

where $I$ and $I_{0}$ are the laser power with and without salt aerosol in the resonator, $\beta_{\text {ext }}$ is the extinction coefficient of the aerosol, and $L_{\text {res }}$ is the length of the resonator, $24.86 \mathrm{~cm}$. The aerosol extinction coefficient calculated from Eq. (3) is compared with the scattering measurements to obtain the scattering calibration factor of Eq. (2). Figure 1a shows the linear regression between the measured extinction and scattering in which the near unity value of $R^{2}$ depicts the excellent correlation between these quantities. Also note the slope of the regression line is near unity, which means the extinc- tion was overwhelmingly due to scattering and no further adjustments are needed for the scattering calibration. After the scattering calibration, the process was repeated with kerosene soot for absorption calibration. Figure $1 \mathrm{~b}$ shows the linear regression between the absorption measurements and extinction-scattering calculation. The slope of the regression line indicates that measured absorption coefficients at $355 \mathrm{~nm}$ should be increased by a factor of 1.29 to reflect this improvement of laser power measurement accuracy.

\subsection{Laboratory generated aerosols}

This section presents the absorption and scattering coefficients measured for three different types of laboratorygenerated aerosols. These include purely scattering salt $(\mathrm{NaCl})$ aerosol, strongly absorbing kerosene soot aerosol, and short-wavelength absorbing incense aerosol. Besides functioning as instrument performance tests, these measurements provide an opportunity for the analysis of the wavelength dependence of absorption and scattering for a range of aerosols that might be representative of atmospheric aerosols in different locations and during different events.

Incense is used to produce fragrances for ceremonial purposes and in residential homes. A wide variety of substances are used to produce incense, including wild flowers, strawberries, sandal wood and other aromatic woods, and resins. Burning incense produces mostly organic compounds including polycyclic aromatic hydrocarbons (PAHs), aromatic aldehydes, and aliphatic aldehydes, with a particle mass median aerodynamic diameter ranging from 150 to $300 \mathrm{~nm}$ (Ji et al., 2010; Yang et al., 2007). The incense used for this study was manufactured in India by coating the pulverized wooden materials and other ingredients on a supporting wooden core and had brown color. One incense stick was ignited in a chamber and the flame was immediately extinguished to obtain smoke from the smoldering phase. Incense is a good aerosol source that has strong absorption at shorter wavelengths due to $\mathrm{BrC}$ and can be used as surrogate for smoldering biomass combustion.

Kerosene soot aerosol has been employed extensively in the laboratory to calibrate the PA absorption measurements, to evaluate the measurements and precision of aerosol light absorption measuring instruments, and to study the aerosol absorption and scattering in external and internal mixing states (Arnott et al., 2000, 2005a; Petzold et al., 2005; Sheridan et al., 2005). It is a surrogate for diesel soot and exhibits nearly inverse wavelength dependence of the aerosol light absorption coefficient (Sheridan et al., 2005).

Calculation of Ångström exponent of absorption (AEA), Ångström exponent of scattering (AES) and single scattering albedo (SSA)

AEA is used to analyze the spectral dependence of aerosol light absorption, to characterize the aerosol composition, and 
to model aerosol radiative forcing. The aerosol light absorption at a single wavelength can be extrapolated to other wavelengths by a power law relationship as

$\beta_{\mathrm{abs}}(\lambda)=C \cdot \lambda^{-\alpha_{\mathrm{abs}}}$

where $\beta_{\text {abs }}(\lambda)$ is the aerosol absorption coefficient at the wavelength $\lambda$ of the light, $C$ is a constant independent of wavelength, and $\alpha_{\mathrm{abs}}$ is the AEA. The AEA, $\alpha_{\mathrm{abs}}\left(\lambda_{1}, \lambda_{2}\right)$ can be calculated from the aerosol light absorption coefficient measured at two different wavelengths $\lambda_{1}$ and $\lambda_{2}$ as (Moosmüller et al., 2011)

$\alpha_{\mathrm{abs}}\left(\lambda_{1}, \lambda_{2}\right)=-\frac{\ln \left(\beta_{\mathrm{abs}}\left(\lambda_{1}\right) / \beta_{\mathrm{abs}}\left(\lambda_{2}\right)\right)}{\ln \left(\lambda_{1} / \lambda_{2}\right)}$.

For small size parameter, absorbing spherical particles with a wavelength independent refractive index, AEA = 1 (Moosmüller and Arnott, 2009; van de Hulst, 1981).

The Angström exponent of scattering (AES) is used to characterize aerosol size. Like AEA, AES is also a power law relationship can be calculated with the Eqs. (4) and (5) by using aerosol scattering coefficients $\left(\beta_{\text {sca }}\right)$. The magnitude of AES approaches a value of 4 for small particles and approaches 0 for large particles with a wavelengthindependent refractive index (Bohren and Huffman, 1998). Another calculated optical property is the single scattering Albedo (SSA), which is defined as the ratio of scattering coefficient $\beta_{\mathrm{sca}}$ to the extinction coefficient, $\beta_{\mathrm{abs}}+\beta_{\mathrm{sca}}$ as

$\mathrm{SSA}=\frac{\beta_{\mathrm{sca}}}{\beta_{\mathrm{sca}}+\beta_{\mathrm{abs}}}$.

Power law relationships, Eqs. (4) and (5), were used to calculate AEA and AES to study the spectral variations of these quantities for laboratory aerosol and are plotted in Fig. 2a. Here, the AEA is the negative slope of the $\beta_{\text {abs }}$ as a function of available wavelengths: $355,405,532,870$, and $1047 \mathrm{~nm}$ in a log-log plot. The AES is the negative slope of a similar plot excluding the $1047 \mathrm{~nm}$ wavelength where scattering was not measured. The value of AEA is 0.80 for kerosene and 4.53 for incense aerosols. Our AEA of kerosene is comparable the value of 1.01 measured by Schnaiter et al. (2006) for a propane diffusion flame at $\mathrm{C} / \mathrm{O}=0.29$. Ajtai et al. (2010) presented a higher value of 1.24 for spectral range 266-1064 nm with the same $\mathrm{C} / \mathrm{O}$ ratio but slightly different burner type than Schnaiter et al. (2006) by measuring the slope of the log-log plot, as applied in our study. The data shows a curvature of the incense absorption coefficients as a function of wavelength, resulting in a larger AEA for shorter wavelengths than for longer ones. Such a curvature has previously been described for AERONET extinction (Schuster et al., 2006), and for $\mathrm{BrC}$ absorption coefficients using a damped simple harmonic oscillator model (Moosmüller et al., 2011). Further, $\beta_{\text {abs }}$ for incense aerosol at $355 \mathrm{~nm}$ was found to be nearly 20 times higher than the IR $\beta_{\text {abs }}$ at $870 \mathrm{~nm}$. Kerosene soot is a good example of black carbon while incense aerosol is a $\mathrm{BrC}$

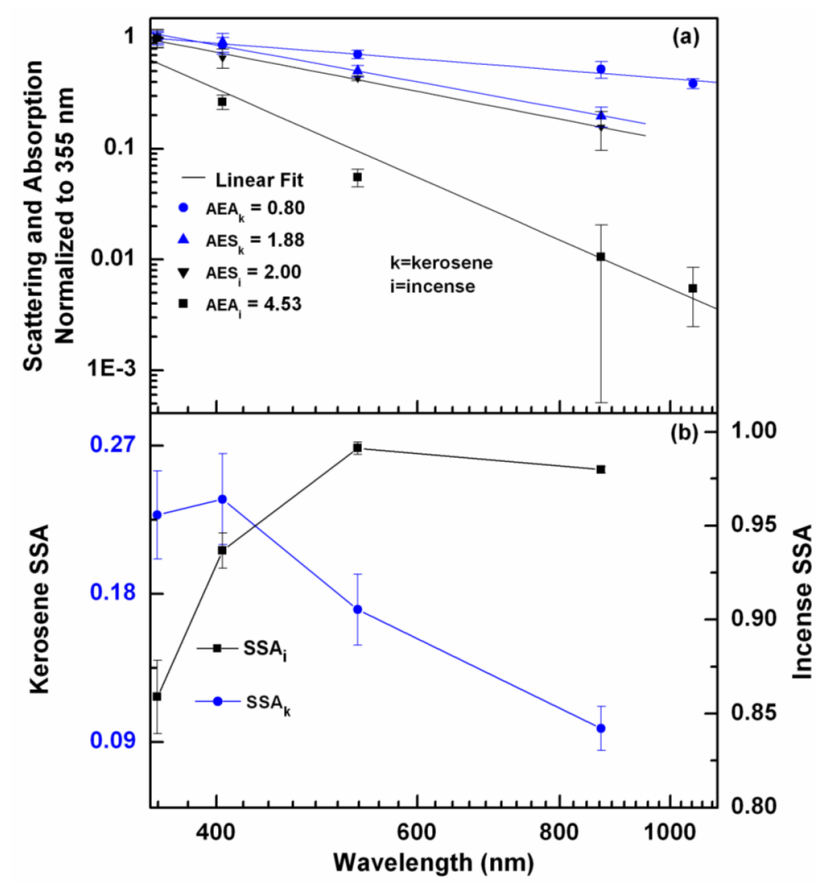

Fig. 2. Intensive aerosol optical properties for kerosene and incense smoke. Ångström exponents of (a) scattering (AES) and absorption (AEA), where error bars indicate the standard deviation of the mean and (b) single scattering albedo (SSA). Uncertainty on SSA was determined by assuming $5 \%$ relative uncertainty in photoacoustic absorption coefficient measurements and $15 \%$ relative uncertainty in scattering coefficient measurements.

example. Similarly, AES is 1.88 for kerosene soot and 2.0 for incense aerosols, indicating larger aerosol size for kerosene soot aerosol than for incense aerosol. AES of kerosene is very close to the value of 1.70 reported by Schnaiter et al. (2006). Figure $2 \mathrm{~b}$ compares SSA for kerosene soot and incense burning aerosols. SSA decreases with wavelength for kerosene soot yet it increases for incense burning aerosol with wavelength, yielding positive and negative Ångström exponents of SSA (AESSA), respectively (Moosmüller and Chakrabarty, 2011). Incense smoke behaves optically similar to primary emissions from biomass burning that have a large OC fraction (Lewis et al., 2008).

\section{Ambient measurements}

\subsection{Meteorological conditions and classification of measurement events}

In this study, we used meteorological data from http:// www.wrcc.dri.edu/rcc.html and balloon soundings from http: //weather.uwyo.edu/upperair/sounding.html pertaining to the Reno area. The data were analyzed from 18 December 2009 to 18 January 2010 to study the enhancement of $\beta_{\text {sca }}$ and $\beta_{\mathrm{abs}}$ by freshly emitted traffic and wood burning aerosols trapped 

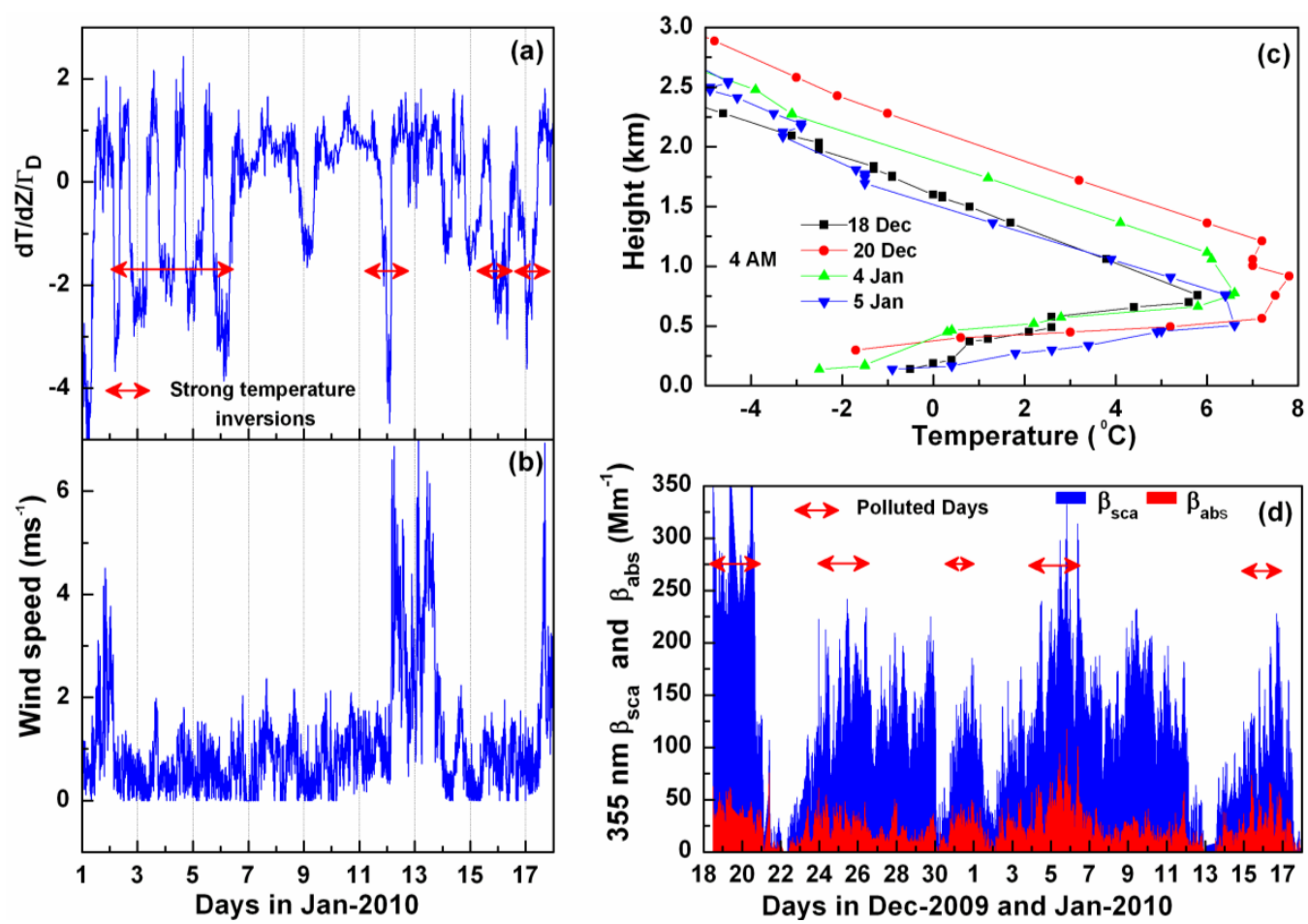

Fig. 3. Meteorology and aerosol optics measurements at $355 \mathrm{~nm}$ during winter 2009/2010 at Reno, Nevada. (a) Temperature gradient normalized to dry adiabatic lapse rate $\left(-9.8^{\circ} \mathrm{C}\right)$, with negative values indicating temperature inversions, (b) wind speed, (c) temperature profiles from radiosonde launches, whereas the height is above the ground level (a.g.l.). Strong temperature inversions are associated with the highly polluted events of the winter season, (d) two minute average of the ambient aerosol scattering and absorption coefficients.

near the surface due to temperature inversion. Temperature generally decreases with altitude in the lower part of the atmosphere, but during certain meteorological situations, the surface may become colder than the air at higher elevations, leading to temperature inversion conditions, which tend to suppress the vertical mixing of air. During temperature inversion periods, the local health officials of Washoe County, Nevada announced air pollution alerts to encourage inhabitants to refrain from extended outdoor activities, and banned residential wood burning (see, http://www.co.washoe.nv.us/ repository/print_pr.php?article $=8510$ ). The $\beta_{\text {abs }}$ during these conditions was comparable to that of Reno, NV during the California wild fire season in the summer of 2008 and to that in Mexico City (Gyawali et al., 2009; Paredes-Miranda et al., 2009). Figure 3 presents the aerosol time-series of $\beta_{\text {sca }}$ and $\beta_{\text {abs }}$ at $355 \mathrm{~nm}$ in conjunction with meteorological parameters from two near surface stations in Reno separated by an altitude difference of $143 \mathrm{~m}$. Figure $3 \mathrm{a}$ and $\mathrm{b}$ display the temperature gradient normalized by the dry adiabatic lapse rate $\left(-9.8^{\circ} \mathrm{C} \mathrm{km}^{-1}\right)$ and the wind speed, respectively. Large negative values of the normalized temperature gradient indicate the strength of the temperature inversion. Soundings balloons were launched from the National Weather Service office located about $150 \mathrm{~m}$ above the valley floor. Thus the higher than valley floor balloon launch site may underesti- mate the inversion strength. The relatively high wind speed of 6 to $7 \mathrm{~ms}^{-1}$ breaks the temperature inversion on 12 January. Figure $3 \mathrm{c}$ shows the temperature profiles from the morning balloon soundings for major temperature inversion events. Additional short-term temperature inversion of a similar nature took place during December and January. Figure $3 \mathrm{~d}$ displays the two-minute average time-series of $\beta_{\text {sca }}$ and $\beta_{\mathrm{abs}}$ at $355 \mathrm{~nm}$. Four episodes of elevated $\beta_{\mathrm{sca}}$ and $\beta_{\mathrm{abs}}$ are centered on 19 and 25 December 2009, and 6 and 16 January, 2010, and are associated with temperature inversion and diminished wind speed (as shown in Fig. 3a, b, and c). These high pollution episodes were predominantly of local origin, with air trapped in the lower levels due to severe stagnation. Results presented here show that the $355 \mathrm{~nm}$ $\beta_{\text {sca }}$ and $\beta_{\text {abs }}$ of trapped emissions can be ten times greater than those for clean days. For such polluted days, the increased UV extinction slows down the formation of SOA and ozone (Barnard et al., 2008). Based upon the meteorological parameters and the magnitude of $\beta_{\mathrm{sca}}$ and $\beta_{\mathrm{abs}}$, we have classified the measurements made from 18 December to 18 January into two groups: "clean days" and "polluted days". Days were classified as polluted days if the average $\beta_{\text {abs }}$ values at $355 \mathrm{~nm}$ for the particular days were about $40 \mathrm{Mm}^{-1}$ or higher, such as 18 to 20,24 to 26 , and 31 December, 4 to 6 and 15 and 16 January. The $\mathrm{PM}_{2.5}$ mass concentration during 
the polluted days was at least $40 \mu \mathrm{g} \mathrm{m}^{-3}$ (air quality public warning "Sensitive") or as high as $90 \mathrm{\mu g} \mathrm{m}^{-3}$ (air quality public warning "Unhealthy"; see, http://alg.umbc.edu/usaq).

\subsection{Particulate matter (PM) and gaseous pollutant concentrations, and their effects on aerosol optical properties}

This section presents particulate matter (PM) and gaseous pollutant concentrations from an air quality monitoring station (South of the Truckee River, EPA ID\#32-031-0016), $\sim 0.9$ miles from the Department of Physics, University of Nevada, Reno, USA, where the aerosol optics measurements were made. The purpose of this section is to investigate the source contributions to the PM and gaseous pollutants during clean and polluted days. Wood burning results in much more $\mathrm{CO}$ and less $\mathrm{NO}_{\mathrm{x}}\left(\mathrm{NO}_{2}+\mathrm{NO}\right)$ than vehicular emissions (Kirchstetter et al., 1999; Johansson et al., 2004), while diesel vehicles are important $\mathrm{NO}_{\mathrm{x}}$ sources because of high combustion temperature (Lloyd and Cackette, 2001). Biomass burning, especially high-temperature flaming combustion may also generate substantial $\mathrm{NO}_{\mathrm{x}}$ (Chen et al., 2010). Wood combustion is known to contain humiclike substances (Hoffer et al., 2006) or BrC (Chakrabarty et al., 2010) that strongly absorbs in the UV regions while $\mathrm{BC}$ emission from traffic exhibits inverse wavelength dependence of light absorption (Bond and Bergstron, 2006). These evidences have been used to identify the influence of wood burning and traffic emissions using the concurrent multispectral aerosol optical measurements and gaseous pollutant concentration measurements (Sandradewi et al., $2008 \mathrm{a}, \mathrm{b}$ ).

Hourly $\mathrm{PM}_{2.5}$ and $\mathrm{PM}_{10}$ mass concentrations were measured by Beta Attenuation Monitor (BAM) (MetOne SASS), whereas the Federal Reference Method (FRM) was used for 24-h speciation of $\mathrm{PM}_{2.5}$ mass concentrations and additional instruments measured concentrations of gaseous pollutants. The operation of the BAMs has been described in detail elsewhere (Chow et al., 2006; Huang and Tai, 2008; Schwab et al., 2006; Takahashi et al., 2008). The working principle of FRM is described in BGI (2009a, b).

Diurnal concentrations of $\mathrm{CO}, \mathrm{NO}, \mathrm{NO}_{2}, \mathrm{PM}_{2.5}$, and coarse particles $\left(\mathrm{PM}_{10}-\mathrm{PM}_{2.5}\right)$ averaged for clean days and polluted days are shown in Fig. 4. For CO and NO, the maximum values occurred during the morning rush hours, followed by a decrease in those quantities in the late morning due to dilutions of these pollutants and growth of the BL. The diurnal variations of $\mathrm{CO}$ and $\mathrm{NO}_{\mathrm{x}}$ concentrations were strongly correlated with $\beta_{\mathrm{abs}}$ at all wavelengths, both for polluted and clean days. The correlation coefficient $\left(R^{2}\right)$ varied from $0.65\left(\beta_{\text {abs }}\right.$ at $532 \mathrm{~nm}$ with $\left.\mathrm{CO}\right)$ to $0.84\left(\beta_{\text {abs }}\right.$ at $355 \mathrm{~nm}$ with $\mathrm{NO}_{\mathrm{x}}$ ). The high correlation suggests that the $\mathrm{CO}$ and $\mathrm{NO}_{\mathrm{x}}$ emitters might also be high particle emitters (Kirchstetter et al., 1999) that influence the multi-spectral aerosol light absorption and scattering. The fact that the mean AEA value increased from 1.03 to 1.14 (see Table 1) suggests a minor increase in $\mathrm{BrC}$ fraction in organics during relatively clean days. This does not necessarily mean the absence of biomass burning or residential wood burning during the study period, since $\mathrm{BrC}$ formation from wood/biomass burning highly depends on combustion efficiency (CE); low CE leads to $\mathrm{BrC}$ enrichment in the smoke (Chen et al., 2010); in many cases residential wood burning in Reno may be efficient enough to mitigate $\mathrm{BrC}$ emissions. Very low correlation coefficients $\left(R^{2} \sim 0.2\right)$ between $\mathrm{AEA}$ and $\mathrm{CO}$ and $\mathrm{NO}_{\mathrm{x}}$ were found during the study periods, in contrast to a similar study in a Swiss alpine valley that found a much higher correlation $\left(R^{2}=0.5\right)$ for substantial emissions from wood burning and traffic (Sandradewi et al., 2008a). They reported AEA 1.1 for traffic emissions and 1.9 for wood burning. The lower than expected values of AEA during the study period are consistent with the findings that approximately two-thirds of $\mathrm{NH}_{4} \mathrm{NO}_{3}$ were associated with mobile source emissions and one-third with residential wood combustion emissions (Watson et al., 2011). Additionally, lower average values of AEA during polluted days (snow covered and strong temperature inversion episodes) can be associated with increased consumption of gasoline and diesel fuel (due to more frequent snow plowing and blowing) (Watson et al., 2011) that may emit more primary $\mathrm{PM}_{2.5}$ and $\mathrm{NO}_{\mathrm{x}}$ than during the drier periods.

The temperature inversions resulted in high concentrations of PM and gaseous pollutants, as shown in Fig. 4. $\mathrm{PM}_{2.5}$ and coarse particle concentrations exhibited much higher concentrations with pronounced diurnal variation during polluted days. $\mathrm{PM}_{2.5}$ primary emissions are likely influenced by traffic and residential wood combustion (Watson and Chow, 2002). The mid-day peaks of $\mathrm{PM}_{2.5}$ and coarse particles, however, may result from the temporal overlap between the evening rush hour, the secondary aerosol produced during day time, wind-related dust, and traffic resuspension (Stephens et al., 2008).

Figure 5 shows 24 -h averages of $\mathrm{PM}_{2.5}$ component mass concentrations for highly polluted days (18 and 24 December, and 5 January) and relatively clean days (21 December and 14 and 17 January). The comparison shows slightly higher concentrations of organic material, much higher quantities of ammonium nitrate $\left(\mathrm{NH}_{4} \mathrm{NO}_{3}\right)$, and a higher amount of unexplained mass during the polluted days. The unexplained mass highly correlates with the $\mathrm{NH}_{4} \mathrm{NO}_{3}$. Furthermore, $\mathrm{NH}_{4} \mathrm{NO}_{3}$ was the primary cause of the lift in the $\mathrm{PM}_{2.5}$ mass concentrations over the $35 \mathrm{\mu gm}^{-3}$ threshold during polluted days. Nitric acid $\left(\mathrm{HNO}_{3}\right)$ is formed from oxidation of $\mathrm{NO}_{\mathrm{x}}\left(\mathrm{NO}_{2}+\mathrm{NO}\right)$ via either photochemical or nighttime reactions (Watson and Chow, 2002). $\mathrm{NH}_{4} \mathrm{NO}_{3}$ is formed by the reaction of $\mathrm{HNO}_{3}$ and ammonia $\left(\mathrm{NH}_{3}\right)$ from agricultural activities. $\mathrm{NH}_{4} \mathrm{NO}_{3}$ exhibits higher hygroscopic growth, increasing the amount of light scattering and direct radiative forcing by ambient aerosols (Crosier et al., 2007). The consistently higher values of $\beta_{\text {sca }}$ at all wavelengths during polluted episodes (see Fig. 6b) can be attributed to dominance of $\mathrm{NH}_{4} \mathrm{NO}_{3}$. In addition, there is a possibility of the formation 
Table 1. Mean values of SSA, AEA, and AES for clean (C) and polluted (P) days. For AEA and AES the reference wavelength is 870 nm.

\begin{tabular}{rrrrrrr}
\hline Wavelength & SSA C & SSA P & AEA C & AEA P & AES C & AES P \\
\hline $355 \mathrm{~nm}$ & $0.87 \pm 0.02$ & $0.83 \pm 0.02$ & $1.14 \pm 0.12$ & $1.03 \pm 0.09$ & $1.63 \pm 0.09$ & $1.73 \pm 0.06$ \\
$405 \mathrm{~nm}$ & $0.80 \pm 0.02$ & $0.78 \pm 0.02$ & $1.12 \pm 0.12$ & $0.99 \pm 0.07$ & $1.11 \pm 0.15$ & $1.38 \pm 0.09$ \\
$532 \mathrm{~nm}$ & $0.82 \pm 0.03$ & $0.78 \pm 0.02$ & $1.00 \pm 0.05$ & $0.78 \pm 0.04$ & $1.16 \pm 0.18$ & $1.42 \pm 0.15$ \\
$870 \mathrm{~nm}$ & $0.81 \pm 0.03$ & $0.72 \pm 0.03$ & & & & \\
\hline
\end{tabular}

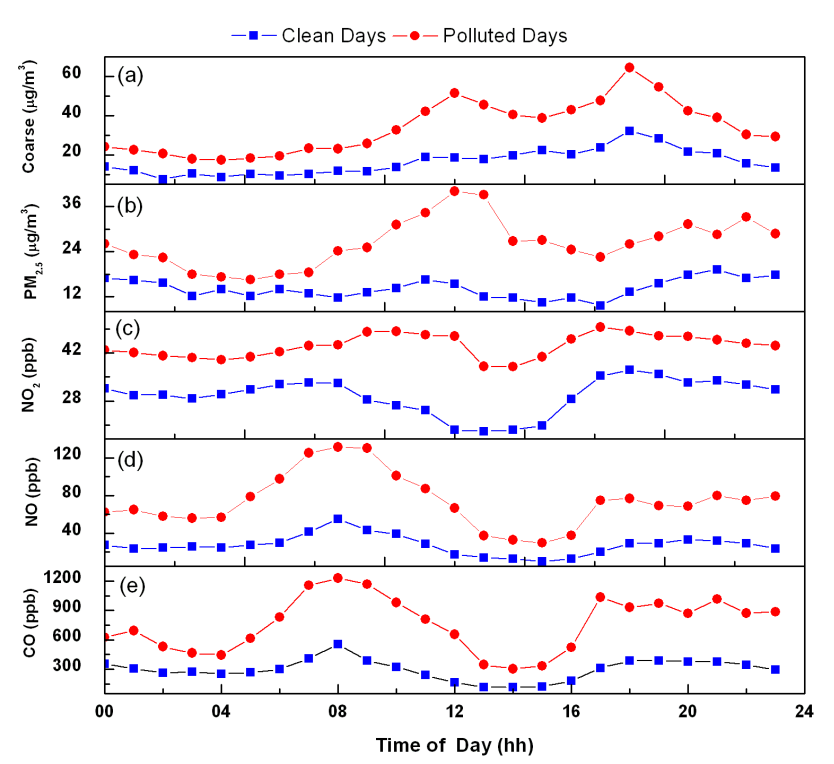

Fig. 4. Diurnal variation of hourly average concentrations of (a) coarse particles, (b) $\mathrm{PM}_{2.5}$, (c) ni tric oxide, (d) nitrogen dioxide, and (e) carbon monoxide.

of organic nitrates in the presence of nitrates and organic species in pollution plumes (Flowers et al., 2010). Particle phase organic nitrates are strong absorbers at UV wavelengths (Jacobson, 1999). The strength of the absorption increases with the acidity of organic nitrates. However, consistently low values of AEA (i.e., less than 1.2) (Fig. 7d) for all pairs including the analysis of multispectral $\beta_{\mathrm{sca}}$ and $\beta_{\mathrm{abs}}$ (presented in the next section) does not support the presence of short wavelength absorbing acidic organic species during polluted days.

\subsection{Ambient aerosol optical properties measurements}

In this section, we present our findings on diurnal variation of half-hour average ambient extensive and intensive aerosol optical properties at wavelengths of $355,405,532$, and $870 \mathrm{~nm}$ from 18 December 2009 to 18 January 2010. These measurements were obtained at the Physics building of the University of Nevada, Reno, USA. PA sampled from

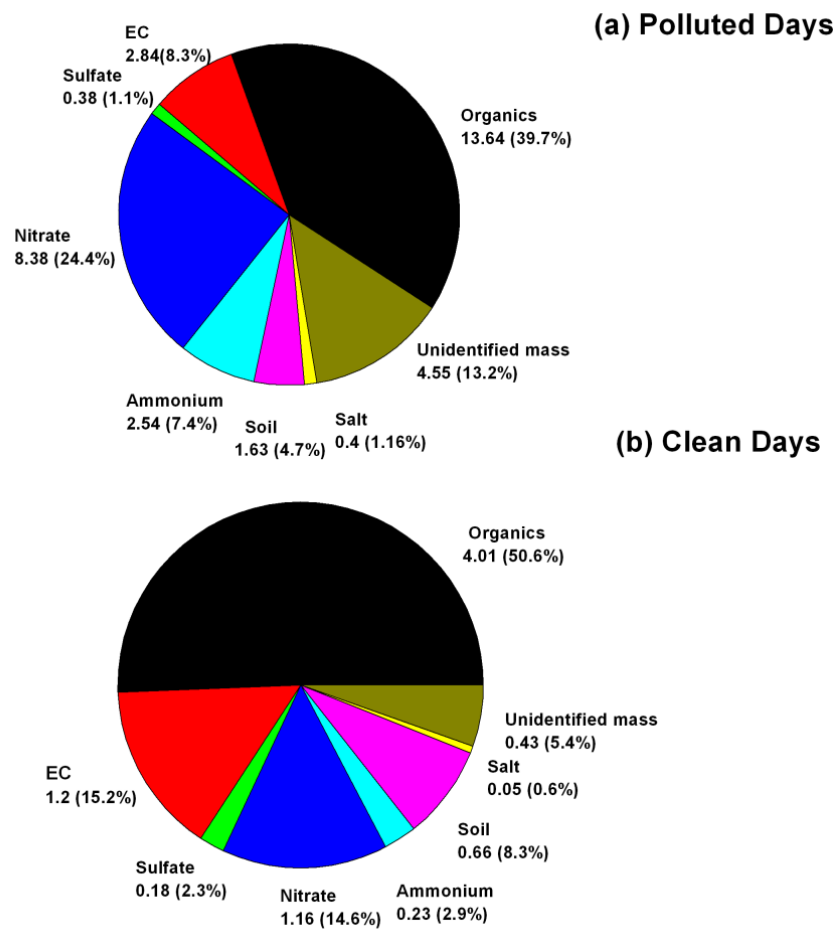

Fig. 5. Twenty-four-hour average $\mathrm{PM}_{2.5}$ component concentrations $\left(\mu \mathrm{gm}^{-3}\right.$ ) for (a) polluted days (18 and 24 December and 5 January) and (b) clean days (21 December and 14 and 17 January).

an inlet at a flow rate of $\sim 3 \mathrm{lpm}$ through a $\sim 3 \mathrm{~m}$ insulated copper inlet line located $\sim 10 \mathrm{~m}$ above the ground. Spectral and diurnal variations of $\beta_{\mathrm{sca}}, \beta_{\mathrm{abs}}$, AES, AEA, and SSA during the study periods were analyzed and classified for "clean days" and "polluted days".

\subsubsection{Spectral and diurnal variations of $\beta_{\text {sca }}$ and $\beta_{\text {abs }}$}

Figure 6a and $\mathrm{b}$ compare the diurnal and spectral variations of half-hour averages of $\beta_{\text {sca }}$ during clean days and polluted days, respectively. These data describe common effects of the BL dynamics, daytime photochemical activity, and additional formation of non-light absorbing particles. Similarly, Fig. $6 \mathrm{c}$ and d compare the $\beta_{\text {abs }}$ measurements. In comparison, peak values of $\beta_{\text {sca }}$ and $\beta_{\text {abs }}$ on stagnant days are nearly twice as large as those values measured on clean days. This can be attributed to the increased concentration of PM, 


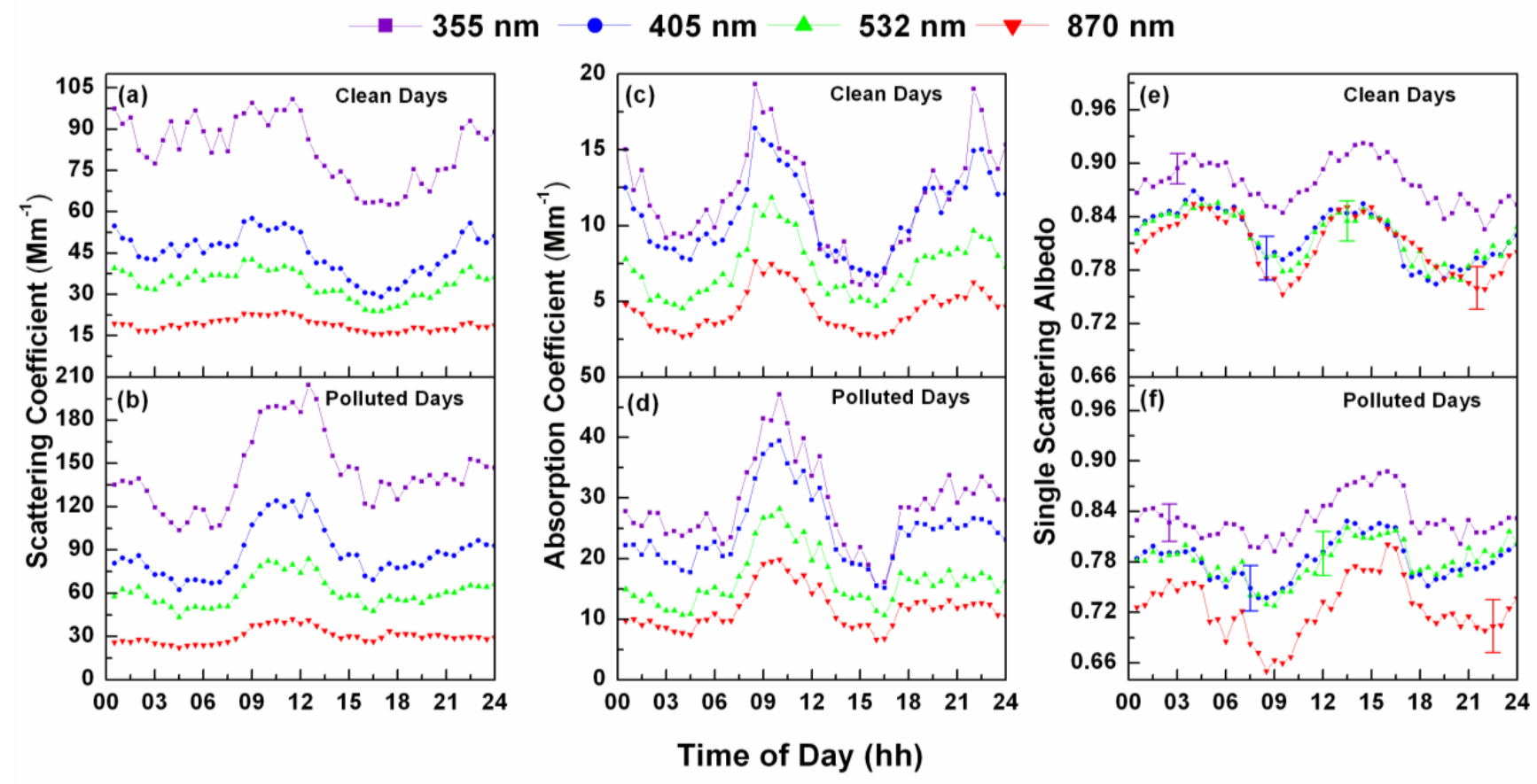

Fig. 6. Diurnal variation of half-hour average ambient aerosol optical properties from 18 December 2009 to 18 January 2010 at wavelengths 355, 405, 532, and $870 \mathrm{~nm}$ for clean and polluted days. (a) and (b) are the scattering coefficients, (c) and (d) are the absorption coefficients, and (e) and (f) are the single scattering albedos (SSA). Uncertainty on SSA was determined by assuming $5 \%$ relative uncertainty in photoacoustic absorption coefficient measurements and $15 \%$ relative uncertainty in scattering coefficient measurements.

specifically ammonium nitrate, soot, and organics during the polluted days. Additionally, during polluted days the peak of the scattering coefficient was $4 \mathrm{~h}$ later than the absorption coefficient peak possibly due to gas to particle formation of secondary aerosol that scatters light effectively, as previously seen in Mexico City (Paredes-Miranda et al., 2009).

\subsubsection{Spectral and diurnal variation of SSA}

SSA is a crucial optical parameter for determining the sign of net radiative forcing by aerosol. The value of 0.85 represents an approximate boundary point. Values above 0.85 generally represent a cooling impact while values less than this quantity represent an heating impact (Hansen et al., 1981). While the temporal and spatial variations of SSA in the atmosphere are associated with BL mechanisms, rush hour activity, and other natural and anthropogenic events, the spectral variations of SSA are dependent on aerosol size, chemical composition, and mixing state. For dust and biomass burning aerosols that absorb significantly at shorter solar wavelengths, SSA generally increases with wavelength, while this tendency reverses for small-particle BC aerosol from vehicular exhaust (Bergstrom et al., 2002; Gyawali et al., 2009; Sokolik and Toon, 1999). Figure 6e and $\mathrm{f}$ show the diurnal and spectral changes in half-hour average of SSA computed with Eq. (6).
The role of temperature inversion on the diurnal evolution of aerosol size and composition is reflected in the magnitude of SSA. Minimum SSA is observed around 09:00 LT, coincident with morning peak traffic, while maximum SSA is observed at 15:00 LT, concurring with the low value of AES and dominance of larger particles as evidenced in Fig. 4a and b. Compared to the other wavelengths, diurnal half-hour SSA at $355 \mathrm{~nm}$ is the highest value, varying from 0.80 to 0.92 . Other wavelengths exhibit a distribution from 0.65 at $870 \mathrm{~nm}$ to 0.88 at $532 \mathrm{~nm}$. Polluted days show less diurnal variation and lower values of SSA due to the averaging effects of multiple days of stagnation.

Though our measurement techniques and approaches are for aerosol sampled close to ground level, it is worthwhile to compare our findings with other published data even if these data are mainly based on remote sensing and focus on the total atmospheric column. Since SSA is an intensive parameter, for well-mixed conditions in-situ ground based and remote sensing measurements should have a similar relationship. Hofzumahaus et al. (2002) applied the best fit of modeled actinic fluxes to spectroradiometer measurements and came up with 0.87 and 0.95 for SSA at $355 \mathrm{~nm}$ for different days in Greece. Corr et al. (2009) found SSA variations from 0.73 to 0.85 at $368 \mathrm{~nm}$ using a multi-filter rotating shadowband radiometer (MFRSR) in Mexico City. Barnard et al. (2008) reported SSA $=0.80$ at $368 \mathrm{~nm}$ using a UVMFRSR technique. These authors have also reported SSA 


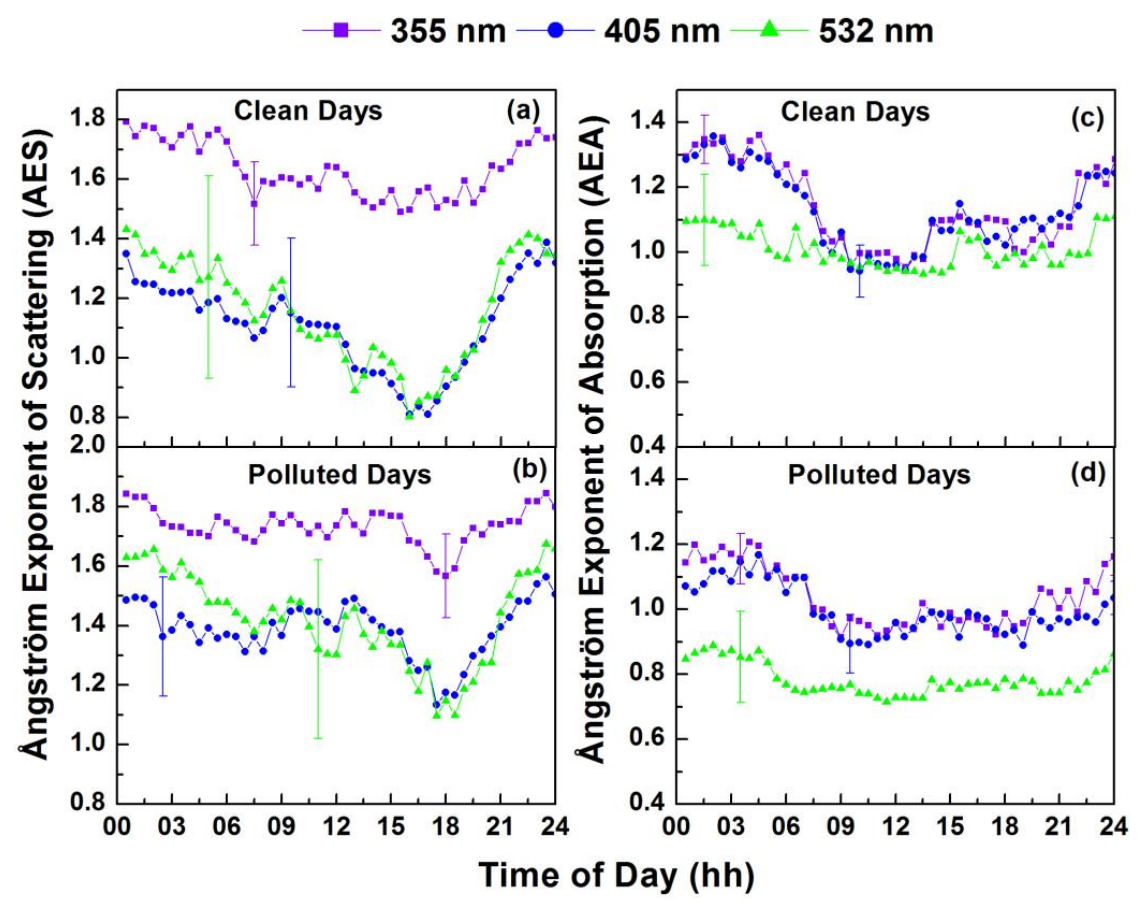

Fig. 7. Diurnal variation of half-hour average ambient intensive aerosol optical properties for clean and polluted days from 18 December 2009 to 18 January 2010 at wavelengths 355, 405, and $532 \mathrm{~nm}$ using $870 \mathrm{~nm}$ as a reference. (a) and (b) Ångström exponent of scattering (AES), (c) and (d) Ångström exponent of absorption (AEA). Uncertainty on AES and AEA were determined by assuming $5 \%$ relative uncertainty in photoacoustic absorption coefficient measurements and $15 \%$ relative uncertainty in scattering coefficient measurements.

for visible wavelengths and acknowledged that the observed lower value towards the UV region, when present, is due to the enhanced absorption by certain organic compounds in aerosols.

\subsubsection{Spectral and diurnal variation of AES}

The wavelength dependence of AES has been used to understand the dominant aerosol size distribution along with the optical properties of biomass burning, urban, and desert dust aerosols (Eck et al., 1999; Reid et al., 1999). Dubovik et al. (2002) described values of Ångström exponent of extinction (AEE) varying from -0.1 to 2.5 to identify aerosol sources including desert dust and biomass burning in their comprehensive survey of aerosol optical properties at locations around the globe (Dubovik et al., 2002). Values of AEE close to 0 occur when the scattering is dominated by large dust particles, and AEE close to 2.5 represents smoke particles. These values were reported from ground-based Sun photometer remote sensing measurement techniques. However, we note that the AEA and the AEE are only comparable when extinction is dominated by scattering.

Figure $7 \mathrm{a}$ and $\mathrm{b}$ present the variations of AES during the clean and polluted days. $\beta_{\text {sca }}(\lambda)$ was used in Eq. 5 for the calculations of AES, where $870 \mathrm{~nm}$ was taken as the reference wavelength. Values of AES are large in the early morning, with AES $=1.8$ for the $355 / 870 \mathrm{~nm}$ pair, and around
1.3 for longer-wavelength pairs ( $405 / 870$ and $532 / 870 \mathrm{~nm}$ ), a widely used value for the atmosphere of natural composition. On clean days, AES values for the longer-wavelengths pairs decline continuously after midnight and are at their minimum value of $\sim 0.8$ about four hours after the local noon, at the warmest, most diluted time of the day. The minimum on polluted days occurs six hours after local noon, corresponding to peak particle size. In comparison, AES varies more for all pairs of wavelengths for clean days than on polluted days. The significant diurnal change of AES implies a distinct diurnal cycle for particle size. The size of the freshly emitted particles increases over their atmospheric residence time due to the various phenomena present in atmospheric processing (Reid et al., 1998). As stated above, AES is at its minimum in the later part of the day, indicating the dominance of larger particles as a result of atmospheric aging of aerosols as found in the diurnal variations of particulate matters. Turbulent mixing at the BL thickness peak may enhance coagulation, and repeatedly expose aerosol and precursors to strong UV radiation at the top of the BL. The BL expansion, photo-oxidation, condensation, and coagulation processes smear out the dominance of freshly emitted submicron particles, shifting to the dominance of larger-sized aged aerosol as implied in the diurnal variation of AES and measurements of $\mathrm{PM}_{2.5}$ and coarse particle mass concentrations. 
The minimum of AES for the longer-wavelength pairs occurs two hours later than for clean days, likely as a result of the delay in photo-chemically driven condensational growth of primary aerosols on polluted days. The explanation for the vastly different behavior of AES for the wavelength pair, $355 / 870 \mathrm{~nm}$, is currently unknown but maybe related to significant changes in refractive indices of different PM components between the visible (i.e. 405 and $532 \mathrm{~nm}$ ) and the UV (i.e. $355 \mathrm{~nm}$ ).

\subsubsection{Spectral and diurnal variation of AEA}

AEA responds to the composition, size, and the presence of coatings on aerosol. Recent analysis shows that AEA can be as high as 1.6 even with non-absorbing coatings on BC (Gyawali et al., 2009; Lack and Cappa, 2010). It has been shown that the core size, coating thickness, and complex refractive index of both components play a vital role in the spectral coating enhancement of absorption.

The diurnal variation of AEA is shown in Fig. 7c and d. The diurnal variations at wavelength pairs $355 / 870$, and 405/870 nm exhibit similar behavior, displaying higher values in the early morning and then decreasing by noon and increasing thereafter. The value of AEA at $355 / 870 \mathrm{~nm}$ is as high as 1.4 on clean days during nighttime hours due to biomass burning. For the wavelength pair 532/870 nm AEA is close to one during clean days and has little variation, but remains around 0.8 during polluted days.

AEA depends on the wavelength pair as well as the mixing and coating state of the aerosols. Depending upon the nature of $\mathrm{OA}$, its mass absorption coefficients towards $\mathrm{UV}$ is significantly higher (as high as $12 \mathrm{~m}^{2} \mathrm{~g}^{-1}$ at $350 \mathrm{~nm}$ ) than at mid visible regions (Barnard et al., 2008; Lack and Cappa, 2010). Hence, 355 and $405 \mathrm{~nm}$ absorption is due to OA and $\mathrm{BC}$, whereas 532 and $870 \mathrm{~nm}$ absorption is mainly due to BC. The maximum AEA was found around 1.4 for the pair $355 / 870 \mathrm{~nm}$ and it can be attributed to the presence of OA from wood burning. This value decreases to around 1.0 during morning rush hour when $\mathrm{BC}$ emissions from vehicles are dominant. After noon, the increase in AEA for all pairs is due to the atmospheric processing of aerosols, in which coating, mixing, and coagulation are taking place. We did not observe dramatic variation of AEA for the $355 / 870 \mathrm{~nm}$ pair compared with the $405 / 870 \mathrm{~nm}$ pair. On the other hand, it is interesting to see (Fig. 7d) that AEA remains nearly constant throughout the day. Restrictions against residential wood burning on polluted days may also result in lower AEA values at night than during clean days.

Figure $8 \mathrm{a}$ and $\mathrm{b}$ show the variation of AES and AEA at 355 and $532 \mathrm{~nm}$ with SSA at 355 and $532 \mathrm{~nm}$, respectively. Like SSA, values of AEA are generally larger and more scattered during clean days. Even though the error bars are overlapping or touching in most of the cases, there is the clear distinction between the mean values of intensive aerosol optical properties, i.e., AES, AEA, and SSA for clean days and polluted days (Fig. 8c, d, and e). The mean values of SSA, AEA, and AES are presented in Table 1. The mean values of the AEA for clean days are comparable with the AEA values reported by Ajtai et al. (2011) from field measurements at suburban wintry conditions in Hungary. This demonstrates some similarity of spectral dependence of aerosol light absorption in these two different places.

\section{Summary and conclusions}

A new photoacoustic instrument measuring aerosol light absorption and scattering at $355 \mathrm{~nm}$ was constructed to explore aerosol optical properties in the UV region and to investigate light absorbing organic aerosols. Multispectral photoacoustic measurements of laboratory-generated and ambient aerosols were performed in Reno, Nevada, USA to evaluate the aerosol light absorption and scattering from near UV to near IR. Particulate matter, gaseous pollutants, and meteorological data in combination with aerosol optical properties were used to get insights into the winter-time urban aerosol evolution and composition. Based upon these analyses, the measurement period, from 18 December 2009 to 18 January 2010 has been divided into "polluted days" (temperature inversion) and "clean days" (well-mixed air).

The results lead to the following remarks and conclusions. The AEA is very large for incense (i.e. 4.53) compared with that of kerosene soot (i.e. 0.80), highlighting its use as a surrogate for smoldering phase biomass combustion. The higher mass concentrations of $\mathrm{PM}_{2.5}$ and coarse particles were associated with the intense ground level temperature inversions. The temporal variation of aerosol intensive parameters is much more pronounced on clean days than on polluted days. The strong temperature inversions more than doubled the peak values of diurnal half-hour average of aerosol absorption (i.e. $\beta_{\mathrm{abs} \text { clean }}^{355 \mathrm{~nm}}=18 \mathrm{Mm}^{-1}$, and $\beta_{\mathrm{abs} \text { polluted }}^{355 \mathrm{~nm}}=48 \mathrm{Mm}^{-1}$ ) and scattering coefficients (i.e. $\beta_{\text {scaclean }}^{355 \mathrm{~nm}}=105 \mathrm{Mm}^{-1}$ and $\beta_{\text {sca polluted }}^{355 \mathrm{~nm}}=210 \mathrm{Mm}^{-1}$ ).

Organic species dominated the $\mathrm{PM}_{2.5}$ component mass concentrations during the study periods; however, the low values of AEAs suggest that the light absorbing particles were not dominated by light absorbing organic carbon or $\mathrm{BrC}$ during polluted days. Our work with UV $(355 \mathrm{~nm})$ absorption does not show a strong signature of wood smoke for Reno, in contrast to what has been found in other places (e.g., Sandradewi et al., 2008a, b). Residential wood burning in Reno may be efficient enough to mitigate $\mathrm{BrC}$ emissions. It was concurrently found that approximately two-thirds of nitrate aerosols were associated with mobile source emissions and one-third with residential wood combustion emissions (Watson et al., 2011). The maximum scattering coefficient values during polluted days occurred $4 \mathrm{~h}$ later than the maximum scattering coefficient values on clean days, suggesting that formation of secondary organic aerosol is delayed by the strong temperature inversions during polluted 

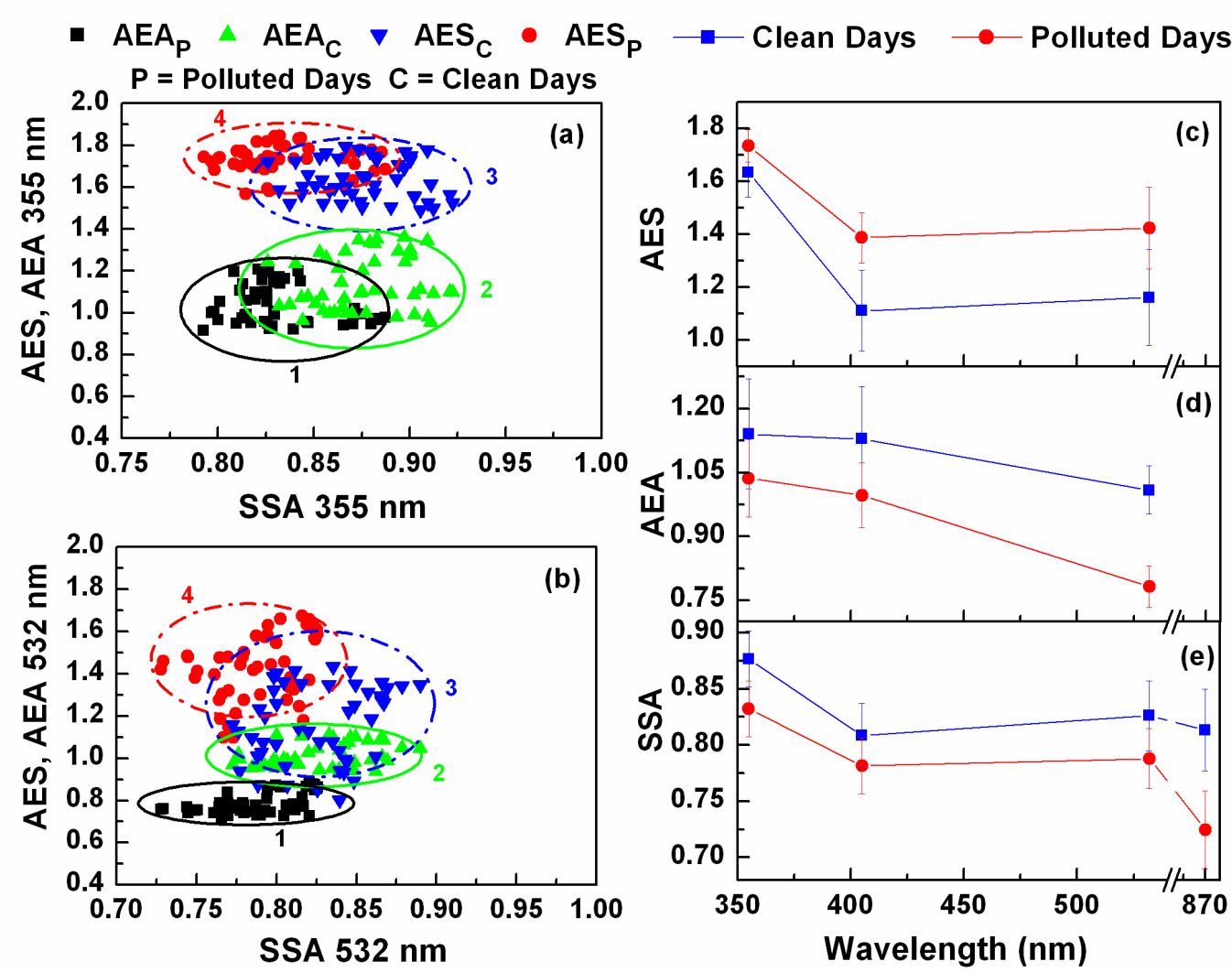

Fig. 8. Ambient intensive aerosol optical properties from 18 December 2009 to 18 January 2010. Half-hour average AES and AEA versus single scattering albedo (SSA) for (a) $355 \mathrm{~nm}$ and (b) $532 \mathrm{~nm}$. Averaged (c) AES and (d) AEA for "clean days" and "polluted days" using $870 \mathrm{~nm}$ as a reference wavelength. (e) similar plot for SSA.

days. The concurrent temporal maximum absorption values during clean and polluted days imply that traffic emissions are the dominant source of multispectral aerosol absorption. In general, SSAs are larger for all wavelengths on clean days (i.e. $\mathrm{SSA}_{\text {clean }}^{355 \mathrm{~nm}}=0.87$ ) than on polluted days (i.e. $\mathrm{SSA}_{\text {polluted }}^{355 \mathrm{~nm}}=0.83$ ). This can be attributed to the increased use of gasoline and diesel engines in the snow removal process and the restrictions on residential wood burning (source of primary organic aerosol) on polluted days.

Acknowledgements. This material is based upon work supported by NASA EPSCoR under Cooperative Agreement No. NNX10AR89A, by NASA ROSES under Grant No. NNX11AB79G, and by the US Department of Energy's Atmospheric System Research (ASR) Program under Contract DE-AC06-76RLO 1830 at Pacific Northwest National Laboratory.

Edited by: M. Gysel

\section{References}

Abu-Rahmah, A., Arnott, W. P., and Moosmüller, H.: Integrating nephelometer with a low truncation angle and an extended calibration scheme, Meas. Sci. Technol., 17, 1723-1732, 2006.

Ajtai, T., Filep, À., Schnaiter, M., Linke, C., Vragel, M., Bozóki, Z., Szabó, G., and Leisner, T.: A novel multi-wavelength photoacoustic spectrometer for the measurement of the UV-visNIR spectral absorption coefficient of atmospheric aerosols, J. Aerosol. Sci., 41, 1020-1029, 2010.

Ajtai, T., Filep, À., Utry, N., Schnaiter, M., Linke, C., Bozóki, Z., Szabó, G., and Leisner, T.: Inter-comparison of optical absorption coefficients of atmospheric aerosols determined by a multiwavelength photoacoustic spectrometer and an Aethalometer under sub-urban wintry conditions, J. Aerosol Sci., 42, 859-866, 2011.

Andreae, M. O. and Gelencsér, A.: Black carbon or brown carbon? The nature of light-absorbing carbonaceous aerosols, Atmos. Chem. Phys., 6, 3131-3148, doi:10.5194/acp-6-3131-2006, 2006.

Arnott, W. P., Moosmüller, H., Rogers, C., Jin, T., and Bruch, R.: Photoacoustic spectrometer for measuring light absorption by aerosols: Instrument description, Atmos. Environ., 33, 2845 2852, 1999. 
Arnott, W. P., Moosmüller, H., and Walker, J.: Nitrogen dioxide and kerosene-flame soot calibration of photoacoustic instruments for measurement of light absorption by aerosols, Rev. Sci. Instrum., 71, 4545-4552, 2000.

Arnott, W. P., Moosmüller, H., and Walker, J.: Nitrogen dioxide and kerosene-flame soot calibration of photoacoustic instruments for measurement of light absorption by aerosols, Rev. Sci. Instrum., 71, 4545-4552, 2000.

Arnott, W. P., Zielinska, B., Rogers, C. F., Sagebiel, J., Park, K., Chow, J., Moosmüller, H., Watson, J. G., Kelly, K., Wagner, D., Sarofim, A., Lighty, J., and Palmer, G.: Evaluation of 1047-nm Photoacoustic Instruments and Photoelectric Aerosol Sensors in Source-Sampling of Black Carbon Aerosol and Particle-Bound PAHs from Gasoline and Diesel Powered Vehicles, Environ. Sci. Technol., 39, 5398-5406, 2005a.

Arnott, W. P., Hamasha, K., Moosmüller, H., Sheridan, P., and Ogren, J.: Towards aerosol light-absorption measurements with a 7-wavelength Aethalometer: Evaluation with a photoacoustic instrument and 3-wavelength nephelometer, Aerosol Sci. Tech., 39, 17-29, 2005b.

Arnott, W. P., Walker, J., Moosmüller, H., Elleman, R., Jonsson, H., Buzorius, G., Conant, W., Flagan, R., and Seinfeld, J.: Photoacoustic insight for aerosol light absorption aloft from meteorological aircraft and comparison with particle soot absorption photometer measurements: DOE Southern Great Plains climate research facility and the coastal stratocumulus imposed perturbation experiments, J. Geophys. Res., 111, D05S02, doi:10.1029/2005JD005964, 2006.

Barnard, J. C., Volkamer, R., and Kassianov, E. I.: Estimation of the mass absorption cross section of the organic carbon component of aerosols in the Mexico City Metropolitan Area, Atmos. Chem. Phys., 8, 6665-6679, doi:10.5194/acp-8-6665-2008, 2008.

Bergstrom, R. W., Russell, P. B., and Hignett, P.: Wavelength Dependence of the Absorption of Black Carbon Particles: Predictions and Results from the TARFOX Experiment and Implications for the Aerosol Single Scattering Albedo, J. Atmos. Sci., 59, 567-577, 2002.

Bergstrom, R. W., Pilewskie, P., Russell, P. B., Redemann, J., Bond, T. C., Quinn, P. K., and Sierau, B.: Spectral absorption properties of atmospheric aerosols, Atmos. Chem. Phys., 7, 5937-5943, doi:10.5194/acp-7-5937-2007, 2007.

Bergstrom, R. W., Schmidt, K., Coddington, O., Pilewskie, P., Guan, H., Livingston, J., Redemann, J., and Russell, P. B.: Aerosol spectral absorption in the Mexico City area: results from airborne measurements during MILAGRO/INTEX B, Atmos. Chem. Phys., 10, 6333-6343, doi:10.5194/acp-10-63332010, 2010.

BGI.: PQ100 Portable PM 10 /TSP / PM 2.5 . Prepared by BGI Incorporated, Waltham, MA, USA, http://www.bgiusa.com/aam/ portable.htm, last access: 06/09/2011, 2009a.

BGI.: PQ200 Ambient Fine Particulate Sampler. Prepared by BGI Incorporated, Waltham, MA, USA, http://www.bgiusa.com/aam/ pq200.htm, last access: 06/09/2011, 2009b.

Bohren, C. F. and Huffman, D. R.: Absorption and scattering of light by small particles, John Wiley \& Sons Inc., 530 pp., 1983.

Bond, T. C.: Spectral dependence of visible light absorption by carbonaceous particles emitted from coal combustion, Geophys. Res. Lett., 28, 4075-4078, 2001.

Bond, T. C. and Bergstrom, R. W.: Light absorption by carbona- ceous particles: An investigative review, Aerosol Sci. Tech., 40, 27-67, 2006.

Chakrabarty, R. K., Moosmüller, H., Chen, L.-W. A., Lewis, K., Arnott, W. P., Mazzoleni, C., Dubey, M. K., Wold, C. E., Hao,W. M., and Kreidenweis, S. M.: Brown carbon in tar balls from smoldering biomass combustion, Atmos. Chem. Phys., 10, 6363-6370, doi:10.5194/acp-10-6363-2010, 2010.

Chen, L.-W. A., Verburg, P., Shackelford, A., Zhu, D., Susfalk, R., Chow, J. C., and Watson, J. G.: Moisture effects on carbon and nitrogen emission from burning of wildland biomass, Atmos. Chem. Phys., 10, 6617-6625, doi:10.5194/acp-10-66172010, 2010.

Chen, C.-L., Tsuang, B.-J., Tu, C.-Y., Cheng, W.-L., and Lin, M.D.: Wintertime vertical profiles of air pollutants over a suburban area in central Taiwan, Atmos. Environ, 36, 2049-2059, 2002.

Chow, J. C. and Watson, J. G., Lowenthal, D. H., Chen, L.-W. A., Tropp, R. J., Park, K., and Magliano, K. L.: $\mathrm{PM}_{2.5}$ and $\mathrm{PM}_{10}$ mass measurements in California's San Joaquin Valley, Aerosol Sci. Technol., 40, 796-810, 2006.

Clarke, A. D., Noone, K. J., Heintzenberg, J., Warren, S. G., and Covert, D. S.: Aerosol light absorption measurement techniques: Analysis and intercomparisons, Atmos. Environ, 21, 1455-1465, doi:10.1016/0004-6981(67)90093-5, 1987.

Corr, C., Krotkov, N., Madronich, S., Slusser, J., Holben, B., Gao, W., Flynn, J., Lefer, B., and Kreidenweis, S.: Retrieval of aerosol single scattering albedo at ultraviolet wavelengths at the T1 site during MILAGRO, Atmos. Chem. Phys., 9, 5813-5827, doi:10.5194/acp-9-5813-2009, 2009.

Crosier, J., Allan, J. D., Coe, H., Bower, K. N., Formenti, P., and Williams, P. I.: Chemical composition of summertime aerosol in the Po Valley (Italy), northern Adriatic and Black Sea, Q. J. R. Meteorol. Soc., 133, 61-75, doi:10.1002/qj.88, 2007.

D’Alessio, A., D'Anna, A., Gambi, G., and Minutolo, P.: The spectroscopic characterization of UV absorbing nanoparticles in fuel rich soot forming flames, J. Aerosol Sci, 29, 397-409, 1998.

Dubovik, O., Holben, B., Eck, T. F., Smirnov, A., Kaufman, Y., King, M. D., Tanre, D., and Slutsker, I.: Variability of absorption and optical properties of key aerosol types observed in worldwide locations, J. Atmos. Sci., 59, 590-608, 2002.

Eck, T. F., Holben, B. N., Reid, J. S., Dubovik, O., Smirnov, A., O'Neill, N. T., Slutsker, I., and Kinne, S.: Wavelength dependence of the optical depth of biomass burning, urban, and desert dust aerosols, J. Geophys. Res., 104, 31333-31349, 1999.

Flowers, B. A., Dubey, M. K., Mazzoleni, C., Stone, E. A., Schauer, J. J., Kim, S.-W., and Yoon, S. C.: Optical-chemicalmicrophysical relationships and closure studies for mixed carbonaceous aerosols observed at Jeju Island; 3-laser photoacoustic spectrometer, particle sizing, and filter analysis, Atmos. Chem. Phys., 10, 10387-10398, doi:10.5194/acp-10-103872010, 2010.

Grisdale, R. O.: The formation of black carbon, J. Appl. Phys, 24, 1082-1091, doi:10.1063/1.1721452, 1953.

Gillis, K. A., Havey, D. K., and Hodges, J. T.: Standard photoacoustic spectrometer: Model and validation using O2 A-band spectra, Rev. Sci. Instrum., 81, 064902-1, 064902-13, 2010.

Gyawali, M., Arnott, W. P., Lewis, K., and Moosmüller, H.: In situ aerosol optics in Reno, NV, USA during and after the summer 2008 California wildfires and the influence of absorbing and non-absorbing organic coatings on spectral light absorption, 
Atmos. Chem. Phys., 9, 8007-8015, doi:10.5194/acp-9-80072009, 2009.

Hansen, J., Johnson, D., Lacis, A., Lebedeff, S., Lee, P., Rind, D., and Russell, G.: Climate Impact of Increasing Atmospheric Carbon Dioxide, Science, 213, 957-966, doi:10.1126/science.213.4511.957, 1981.

Hoffer, A., Gelencser, A., Guyon, P., Kiss, G., Schmid, O., Frank, G. P., Artaxo, P., and Andreae, M. O.: Optical properties of humic-like substances (HULIS) in biomass-burning aerosols, Atmos. Phys. Chem., 6, 3563-3570, doi:10.5194/acp-6-3563-2006, 2006.

Hofzumahaus, A., Kraus, A., Kylling, A., and Zerefos, C. S.: Solar actinic radiation $(280-420 \mathrm{~nm})$ in the cloud-free troposphere between ground and $12 \mathrm{~km}$ altitude: Measurements and model results, J. Geophys. Res., 107, doi:200210.1029/2001JD900142, 2002.

Horvath, H.: Atmospheric light absorption-A review, Atmos. Environ., 27, 293-317, 1993.

Huang, C. H. and Tai, C. Y.: Relative humidity effect on $\mathrm{PM}_{2.5}$ readings recorded by collocated beta attenuation monitors. Environmental Engineering Science, 25, 1079-1089. ISI:000259125600013, 2008

Jacobson, M. Z.: Isolating nitrated and aromatic aerosols and nitrated aromatic gases as sources of ultraviolet light absorption, J. Geophys. Res., 104, 3527-3542, 1999.

Jacobson, M. C., Hansson, H.-C., Noone, K. J., and Charlson, R. J.: Organic atmospheric aerosols: Review and state of the science, Rev. Geophys., 38, 267-294, 2000.

Ji, X., Le Bihan, O., Ramalho, O., Mandin, C., D’Anna, B., Martinon, L., Nicolas, M., Bard, D., and Pairon, J.-C.: Characterization of particles emitted by incense burning in an experimental house, Indoor Air, 20, 147-158, doi:10.1111/j.16000668.2009.00634.x, 2010.

Kikas, U., Reinart, A., Vaht, M., and Veismann, U.: A case study of the impact of boundary layer aerosol size distribution on the surface UV irradiance, Atmos. Environ., 35, 5041-5051, 2001.

Kirchstetter, T. W., Harley, R. A., Kreisberg, N. M., Stolzenburg, M. R., and Hering, S. V.: On-road measurements of fine particle and nitrogen oxide emissions from light-and heavy-duty motor vehicles, Atmos. Environ.,33, 2955-2968, 1999.

Kirchstetter, T. W., Novakov, T., and Hobbs, P. V.: Evidence that the spectral dependence of light absorption by aerosols is affected by organic carbon, J. Geophys. Res., 109, D21208, doi:10.1029/2004JD004999, 2004.

Lack, D. A. and Cappa, C. D.: Impact of brown and clear carbon on light absorption enhancement, single scatter albedo and absorption wavelength dependence of black carbon, Atmos. Chem. Phys., 10, 4207-4220, doi:10.5194/acp-10-4207-2010, 2010.

Levoni, C., Cervino, M., Guzzi, R., and Torricella, F.: Atmospheric aerosol optical properties: a database of radiative characteristics for different components and classes, Appl. Opt., 36, 8031-8041, 1997.

Lewis, K., Arnott, W. P., Moosmüller, H., and Wold, C. E.: Strong spectral variation of biomass smoke light absorption and single scattering albedo observed with a novel dual-wavelength photoacoustic instrument, J. Geophys. Res., 113, D16203, doi:10.1029/2007JD009699, 2008.

Lewis, K. A., Arnott, W. P, Moosmüller, H., Chakrabarty, R. K., Carrico, C. M, Kreidenweis, S. M., Day, D. E., Malm, W.
C., Laskin, A., Jimenez, J. L., Ulbrich, I. M. Huffman, J. A., Onasch, T. B.,Trimborn, A., Lui, L., and Mishchenko, M. I.: Reduction in Biomass Burning Aerosol Light Absorption upon Humidification: Roles of Inorganically-Induced Hygroscopicity, Particle Collapse, and Photoacoustic Heat and Mass Transfer. Atm. Chem. Phys., 9, 8949-8966, doi:10.5194/acp-9-89492009, 2009.

Lloyd, A. C. and Cackette, T. A.: Critical review- Diesel engines: Environmental impact and control, J. Air Waste Manage. Assoc., 51, 809-847, 2001.

Martins, J. V., Artaxo, P., Kaufman, Y. J., Castanho, A. D., and Remer, L. A.: Spectral absorption properties of aerosol particles from 350-2500 nm, Geophys. Res. Lett., 36, L13810, doi:200910.1029/2009GL037435, 2009.

Moosmüller, H. and Arnott, W. P.: Particle Optics in the Rayleigh Regime, J. Air Waste Manage., 59, 1028-1031, 2009.

Moosmüller, H. and Chakrabarty, R. K.: Technical Note: Simple analytical relationships between Ångström coefficients of aerosol extinction, scattering, absorption, and single scattering albedo, Atmos. Chem. Phys., 11, 10677-10680, doi:10.5194/acp-11-10677-2011, 2011.

Moosmüller, H., Arnott, W. P., Rogers, C. F., Chow, J. C., Frazier, C. A., Sherman, L. E., and Dietrich, D. L.: Photoacoustic and filter measurements related to aerosol light absorption during the Northern Front Range Air Quality Study (Colorado 1996/1997), J. Geophys. Res., 103, doi:10.1029/98JD02618, 1998.

Moosmüller, H., Chakrabarty, R. K., and Arnott, W. P.: Aerosol light absorption and its measurement: A review, J. Quant. Spectrosc. Radiat. Transfer, 110, 844-878, 2009.

Moosmüller, H., Chakrabarty, R. K., Ehlers, K. M., and Arnott, W. P.: Absorption Ångström coefficient, brown carbon, and aerosols: basic concepts, bulk matter, and spherical particles, Atmos. Chem. Phys., 11, 1217-1225, doi:10.5194/acp-11-12172011, 2011.

Paredes-Miranda, G., Arnott, W. P., Jimenez, J. L., Aiken, A. C., Gaffney, J. S., and Marley, N. A.: Primary and secondary contributions to aerosol light scattering and absorption in Mexico City during the MILAGRO 2006 campaign, Atmos. Chem. Phys., 9, 3721-3730, doi:10.5194/acp-9-3721-2009, 2009.

Petzold, A. and Schönlinner, M.: Multi-angle absorption photometry - a new method for the measurement of aerosol light absorption and atmospheric black carbon, J. Aerosol Sci., 35, 421-441, 2004.

Reid, J. S., Hobbs, P. V., Ferek, R. J., Blake, D. R., Martins, J. V., Dunlap, M. R., and Liousse, C.: Physical, chemical, and optical properties of regional hazes dominated by smoke in Brazil, J. Geophys. Res., 103, 32059-32080, 1998.

Reid, J. S., Eck, T., Christopher, S., Hobbs, P. V., and Holben, B. N.: Use of the Angstrom exponent to estimate the variability of optical and physical properties of aging smoke particles in Brazil, J. Geophys. Res., 104, 27473-27489, 1999.

Roden, C. A., Bond, T. C., Conway, S., Benjamin, A., and Pinel, A. B. O.: Emission factors and real-time optical properties of particles emitted from traditional wood burning cookstoves, Environ. Sci. Technol., 40, 6750-6757, 2006.

Sandradewi, J., Prévôt, A. S. H., Szidat, S., Perron, N., Alfarra, M. R., Lanz, V. A., Weingartner, E., and Baltensperger, U.: Using aerosol light absorption measurements for the quantitative determination of wood burning and traffic emission contributions 
to particulate matter, Environ. Sci. Technol., 42, 3316-3323, doi:10.1021/es702253m, 2008a.

Sandradewi, J., Prévôt, A. S. H., Weingartner, E., Schmidhauser, R., Gysel, M., and Baltensperger, U.: A study of wood burning and traffic aerosols in an Alpine valley using a multi-wavelength Aethalometer, Atmos. Environ., 42, 101-112, 2008b.

Schuster, G. L., Dubovik, O., and Holben, B. N.: Angstrom exponent and bimodal aerosol size distributions, J. Geophys. Res., 111, D07207, doi:10.1029/2005JD006328, 2006.

Schwab, J. J., Felton, H. D., Rattigan, O. V., and Demerjian, K. L.: New York state urban and rural measurements of continuous $\mathrm{PM}_{2.5}$ mass by FDMS, TEOM, and BAM, J. Air Waste Manage. Assoc., 56, 372-383, 2006.

Schnaiter, M., Gimmler, M., Llamas, I., Linke, C., Jäger, C., and Mutschke, H.: Strong spectral dependence of light absorption by organic carbon particles formed by propane combustion, Atmos. Chem. Phys., 6, 2981-2990, doi:10.5194/acp-6-2981-2006, 2006.

Seinfeld, J. H. and Pandis, S. N.: Atmospheric Chemistry and Physics: From Air Pollution to Climate Change, 2nd edn., Wiley, Hoboken, NJ, USA, 2006.

Sheridan, P., Arnott, W. P., Ogren, J., Andrews, E., Atkinson, D., Covert, D., Moosmüller, H., Petzold, A., Schmid, B., Strawa, A., Varma, R., and Virkkula: The Reno Aerosol Optics Study: An evaluation of aerosol absorption measurement methods, Aerosol Sci. Tech., 39, 1-16, doi:10.1080/027868290901891, 2005.

Silva, P., Vawdrey, E., Corbett, M., and Erupe, M.: Fine particle concentrations and composition during wintertime inversions in Logan, Utah, USA, Atmos. Environ., 41, 5410-5422, doi:10.1016/j.atmosenv.2007.02.016, 2007.

Sokolik, I. and Toon, O.: Incorporation of mineralogical composition into models of the radiative properties of mineral aerosol from UV to IR wavelengths, J. Geophys. Res., 104, 9423-9444, 1999.

Stephens, S., Madronich, S., Wu, F., Olson, J. B., Ramos, R., Retama, A., and Muñoz, R.: Weekly patterns of México City's surface concentrations of $\mathrm{CO}, \mathrm{NO}_{\mathrm{x}}, \mathrm{PM}_{10}$ and $\mathrm{O}_{3}$ during 19862007, Atmos. Chem. Phys., 8, 5313-5325, doi:10.5194/acp-85313-2008, 2008.
Sun, H., Biedermann, L., and Bond, T.: Color of brown carbon: A model for ultraviolet and visible light absorption by organic carbon aerosol, Geophys. Res. Lett. 34, L17813, doi:10.1029/2007GL029797, 2007.

Taylor, T., L'Ecuyer, T., Slusser, J., Stephens, G., and Goering, C.: An operational retrieval algorithm for determining aerosol optical properties in the ultraviolet, J. Geophys. Res., 113, D03201, doi:10.1029/2007JD008661, 2008.

Tian, G., Moosmüller, H., and Arnott, W. P.: Simultaneous photoacoustic spectroscopy of aerosol and oxygen A-band absorption for the calibration of aerosol light absorption measurements, Aerosol. Sci. Technol., 43, 1084-1090, 2009.

van de Hulst, H. C.: Light Scattering by Small Particles, Dover Publications, Inc., New York, USA, 453 pp., 1981.

Watson, J. G. and Chow, J. C.: A wintertime $\mathrm{PM}_{2.5}$ episode at the Fresno, CA, supersite, Atmos. Environ, 36, 465-475, 2002.

Watson, J. G., Chow, J. C., Chen, L.-W. A., Green, M. C., and Kohl, S. D.: Wintertime $\mathrm{PM}_{2.5}$ source contributions in Reno, NV. A report prepared by Desert Research Institute, Reno, NV, for Washoe County Health District, Air Quality Division, Reno, NV, 2011.

Wentzel, M., Gorzawski, H., Naumann, K., Saathoff, H., and Weinbruch, S.: Transmission electron microscopical and aerosol dynamical characterization of soot aerosols, J. Aerosol Sci., 34, 1347-1370, 2003.

Yang, C., Lin, T., and Chang, F.: Particle size distribution and PAH concentrations of incense smoke in a combustion chamber, Environ. Pollut., 145, 606-615, doi:10.1016/j.envpol.2005.10.036, 2007.

Zaveri, R. A., Berkowitz, C. M., Brechtel, F. J., Gilles, M. K., Hubbe, J. M., Jayne, J. T., Kleinman, L. I., Laskin, A., Madronich, S., Onasch, T. B., Pekour, M. S., Springston, S. R., Thornton, J. A., Tivanski, A. V., and Worsnop, D. R.: Nighttime chemical evolution of aerosol and trace gases in a power plant plume: Implications for secondary organic nitrate and organosulfate aerosol formation, $\mathrm{NO}_{3}$ radical chemistry, and $\mathrm{N}_{2} \mathrm{O}_{5}$ heterogeneous hydrolysis, J. Geophys. Res., 115, D12304, doi:10.1029/2009JD013250, 2010. 